\title{
Bending deflection reinforced concrete elements determination
}

\author{
Dmitriy Kochkarev ${ }^{1,}$, Taliat Azizov ${ }^{2}$, and Tatyana Galinska ${ }^{3}$ \\ ${ }^{1}$ National University of Water and Environmental Engineering, 33028 Rivne, Soborna St., 11, \\ Ukraine \\ ${ }^{2}$ Pavlo Tychyna Uman State Pedagogical University, 20300 Uman, Sadova St., 2, Ukraine \\ ${ }^{3}$ Poltava National Technical Yuri Kondratyuk University, 36011 Poltava, Pershotravnevyi avenue, 24, \\ Ukraine
}

\begin{abstract}
Longitudinal reinforced concrete elements stiffness exhaustion, often used in building practice, precedes obtaining bearing capacity, and therefore deflections determination becomes a determining factor in their design. In connection with it precise methods for determining such reinforced concrete elements deflections become especially relevant. The elastic-plastic properties of concrete and cracks in the stretched zone of reinforced concrete elements lead to a significant change in their bending stiffness. That is why the deflections determined by the materials classical resistance formulas differ significantly from the real ones. A large quantity of methods for determining deflections is based on the elastic characteristics correction of reinforced concrete elements consolidated section. Such methods, although providing calculation satisfactory results, are rather approximate and have empirical nature, due to it they have limited application. More precise calculation methods consist of curvature usage to determine deflections. The curvature of reinforced concrete elements cross sections is determined directly from the equilibrium equations, which are written taking into account nonlinear materials deformation diagrams. Calculation examples for bending reinforced concrete elements deflection are given.
\end{abstract}

\section{Review of recent studies and publications}

Bending deflection reinforced concrete elements determination is a very topical task, when designing large spans reinforced concrete elements. It is due to the connection with the fact that the elastic-plastic properties of concrete and cracks in the stretched zone of reinforced concrete elements lead to a significant change in their stiffness. That is why the deflections determined by the formulas of the classical materials resistance differ significantly from the real ones. A large number of methods for determining deflections are based on the correction of elastic characteristics of reinforced concrete elements consolidated sections $[1,2]$. The most well-known is the Branson formula [3], which modified expression is included in the design norm AS3600-2001 [4]. Subsequently, it was corrected by such

\footnotetext{
${ }^{*}$ Corresponding author: $\underline{\operatorname{dim} 7 @ \text { ukr.net }}$
} 
researchers as Lutz [5], Al-Zaid, Al-Shaikh and Abu-Hussein [6], Fikry and S. Thomas [7]. The proposed methods, providing satisfactory calculation results, are rather approximate and have an empirical nature, due to their limited application.

More precise calculation methods are in curvature usage to determine deflections. Reinforced concrete elements cross sections curvature is determined directly from the equilibrium equations, which are written taking into account nonlinear materials deformation diagrams or piecewise linear diagrams $[8,9]$. There are methods where a reinforced concrete beam is considered as a composite rod [10]. These methods are sufficiently precise, but not convenient in the complex repeatedly statically uncertain systems calculation.

Let's show curvature changes schedule in the bending reinforced concrete elements sections (Fig. 1). In Fig. 1 with points the stages of the cross sections stress-strain state are marked. Particular, p. 1 corresponds to the moment of cracks formation; p. 3 is fluidity obtaining moment in the stretched armature, p. 4 and p.5 are destruction moment. At equation each stage, the equilibrium has its own form. Single dependence adoption on the entire gap necessarily leads to adjusting empirical coefficients usage. That is why the vast majority of scientists make curvature approximation only within certain areas. But all these methods are also approximate. It leads to averaged section concept usage. A more precise method for calculating deflections is to consider separate cross sections with cracks and between cracks, which allows getting a complete picture of a cracked formation. For most engineering calculations it is quite enough to use methods using the averaged section, which are proposed to be considered.

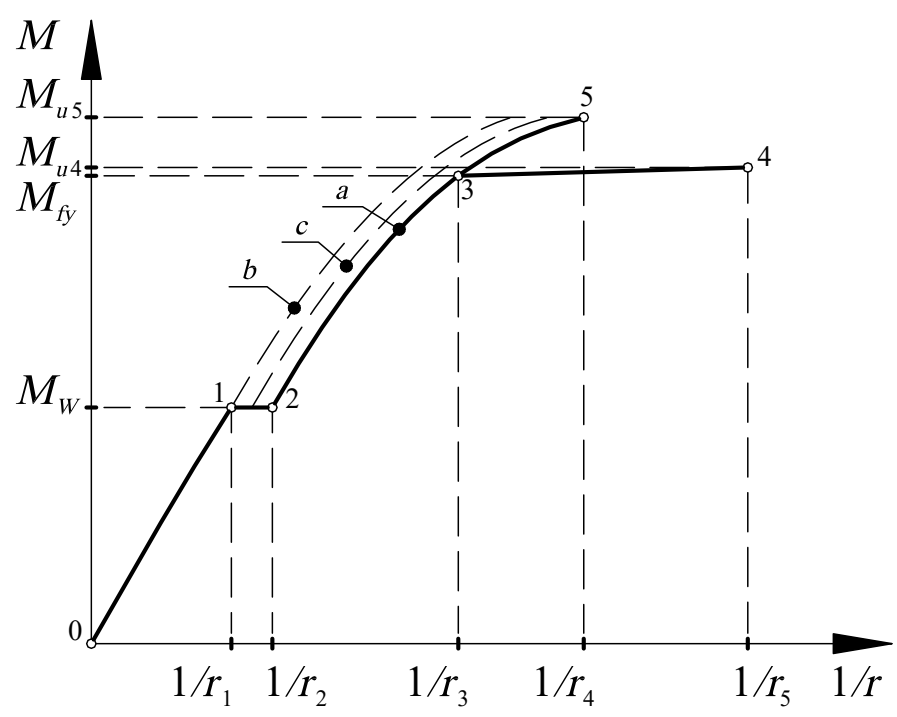

Fig. 1. "Moment-curvature" for bending elements dependence.

\section{Basic material and results}

Consider the methods for calculating bending deflection reinforced concrete elements, which are based on the method of calculation resistance of reinforced concrete [9] and on the use of cross-section curvature. In this case, deflections are determined by the known expression Mora 


$$
f=\int_{0}^{l} \bar{M}_{x}\left(\frac{1}{r}\right)_{x} d x .
$$

Getting the general equation of the continuous curvature function $(1 / r)_{x}$ along the length of the element is quite complicated due to the change in the deformation properties and cracks presence in the stretched zone. Therefore, for the practical calculations, the Simpson formula is used, using the discrete values of the curvature defined in the specific sections $(1 / r)_{x}$

$$
f=\frac{l^{2}}{3 n}\left[\begin{array}{l}
\alpha_{0} 1 / r_{0}+\alpha_{n} 1 / r_{n}+4\left(\alpha_{1} 1 / r_{1}+\alpha_{3} 1 / r_{3}+\ldots+\alpha_{n-1} 1 / r_{n-1}\right) \\
+2\left(\alpha_{2} 1 / r_{2}+\alpha_{4} 1 / r_{4}+\ldots+\alpha_{n-2} 1 / r_{n-2}\right)
\end{array}\right],
$$

where $1 / r_{i}$ is beam curve $i$ - section; $\alpha_{i}$ is unit force influence coefficient at the moment $i$-section; $l$ is span element; $n$ is section quantity along beam length in this case it should be paired.

A simplified equation is used for the preliminary approximation of deflections

$$
f=\frac{1}{r_{m}} k_{m} l^{2}
$$

where $1 / r_{m}$ is curved beam in a dangerous section; $k_{m}$ is coefficient depending on the calculation scheme.

It is expedient to determine the curvature of an element directly from equations of equilibrium. To do it, take appropriate materials deformation diagram for concrete and reinforcement. The curvature values are determined by the formula

$$
1 / r=\frac{\sum \varepsilon}{d}
$$

where $\sum \varepsilon$ is a total relative deformation of the compressed concrete edge and stretched reinforced; $d$ is working section height.

Total relative deformations value of compressed edge concrete and stretched reinforcement. $\sum \varepsilon$ is in a clear functional dependence on the percentage of reinforcement $\rho_{f}$, stresses in reinforced concrete $\sigma_{z M}$, concrete class $C$ and reinforced class $A$

$$
\sum \varepsilon=f\left(\rho_{f}, \sigma_{z M}, C, A\right) .
$$

For an example, let's look at a fragment of the table (see Table 1), which allows to determine the total relative deformation of the compressed concrete edge and the stretched reinforcement $\sum \varepsilon$.

The tensioning in reinforced concrete are determined by

$$
\sigma_{z \grave{I}}=\frac{\grave{I}}{W_{c}},
$$


where $M$ is bending moment in the section; $W_{c}$ is elastic moment of working section concrete resistance, $W_{c}=b d^{2} / 6$.

Another method for determining deflections is to approximate the dependence $M-1 / r$. Such an approximation can be carried out only within the stages of the stressstrain state. Since the deflections of reinforced concrete elements, mainly, are within the range of 0.5-0.85 from the destructive load, therefore the approximation of dependence $M-1 / r$ it is worth doing exactly within such limits. Dependence areas $M-1 / r$ in such limits corresponds to the work of reinforced concrete elements until the yield strength in the reinforcement is reached. Approximation of the diagram section straight lines $M-1 / r$ displayed sufficient convergence, where the correlation coefficient is within the range of $0.956-0.98$ for various reinforcement proportion, reinforcement and concrete classes. For practical calculations, it is more expedient to perform approximation in coordinate's $\sigma_{z \grave{I}}-\sum \varepsilon$.

As a result of the approximation by the least squares method, the dependence of the form is obtained

$$
\sigma_{z M}=a_{i}+b_{i} \sum \varepsilon,
$$

where $a_{i}, b_{i}$ are power factors in $\mathrm{MPa}$, which depend on the class of concrete and reinforcement.

Table 1. To determinate the stress-deformed state parameters of bending reinforced concrete elements for short-term load (reinforcement A400C).

\begin{tabular}{|c|c|c|c|c|c|c|c|c|c|c|}
\hline \multirow{3}{*}{$\begin{array}{c}\text { Concrete } \\
\text { class }\end{array}$} & \multirow{3}{*}{$\begin{array}{l}\text { Load } \\
\text { level }\end{array}$} & \multicolumn{9}{|c|}{ Proportion of reinforcement, $\rho_{f}$} \\
\hline & & \multicolumn{3}{|c|}{1} & \multicolumn{3}{|c|}{2} & \multicolumn{3}{|c|}{3} \\
\hline & & $\begin{array}{l}\sigma_{z M} \\
\mathrm{MPa}\end{array}$ & $\underset{\times 10^{4}}{\sum \varepsilon}$ & $\begin{array}{c}\sigma_{s,} \\
\mathrm{MPa}\end{array}$ & $\begin{array}{c}\sigma_{z M}, \\
\mathrm{MPa}\end{array}$ & $\begin{array}{c}\sum \varepsilon \\
\times 10^{4}\end{array}$ & $\begin{array}{c}\sigma_{s} \\
\mathrm{MPa}\end{array}$ & $\begin{array}{c}\sigma_{z M}, \\
\mathrm{MPa}\end{array}$ & $\sum_{\times 10^{4}}$ & $\begin{array}{c}\sigma_{s} \\
\mathrm{MPa}\end{array}$ \\
\hline \multirow{6}{*}{$\mathrm{C} 16 / 20$} & $M_{W 1}$ & 3.7 & 3.0 & 31.0 & 5.0 & 3.3 & 30.6 & 6.2 & 3.5 & 30.3 \\
\hline & $M_{W 2}$ & 3.7 & 4.3 & 57.2 & 5.0 & 4.2 & 40.1 & 6.2 & 4.1 & 34.1 \\
\hline & 0.4 & 8.3 & 11.1 & 152.7 & 12.8 & 11.8 & 124.2 & 13.6 & 9.9 & 90.4 \\
\hline & 0.6 & 12.4 & 17.6 & 235.4 & 19.1 & 18.8 & 192.6 & 20.4 & 15.9 & 140.8 \\
\hline & 0.8 & 20.2 & 33.7 & 395.9 & 27.1 & 30.2 & 284.8 & 29.0 & 25.9 & 209.0 \\
\hline & 1.0 & 20.6 & 65.7 & 400.0 & 31.9 & 46.0 & 380.3 & 34.1 & 40.5 & 281.6 \\
\hline \multirow{6}{*}{ C20/25 } & $M_{W 1}$ & 4.1 & 3.0 & 31.8 & 5.4 & 3.3 & 31.4 & 6.7 & 3.5 & 31.1 \\
\hline & $M_{W 2}$ & 4.1 & 4.4 & 63.0 & 5.4 & 4.4 & 43.3 & 6.7 & 4.2 & 36.6 \\
\hline & 0.4 & 8.5 & 10.7 & 155.4 & 14.7 & 12.8 & 142.3 & 16.2 & 11.1 & 106.8 \\
\hline & 0.6 & 12.8 & 16.9 & 239.4 & 22.1 & 20.3 & 219.7 & 24.3 & 17.7 & 165.7 \\
\hline & 0.8 & 20.8 & 31.5 & 400.0 & 31.3 & 31.9 & 322.8 & 34.4 & 28.3 & 244.9 \\
\hline & 1.0 & 21.3 & 72.4 & 400.0 & 36.8 & 49.3 & 400.0 & 40.5 & 43.1 & 323.9 \\
\hline \multirow{6}{*}{$\mathrm{C} 25 / 30$} & $M_{W 1}$ & 4.7 & 3.2 & 33.7 & 6.1 & 3.4 & 33.4 & 7.5 & 3.6 & 33.1 \\
\hline & $M_{W 2}$ & 4.7 & 4.7 & 72.2 & 6.1 & 4.7 & 48.7 & 7.5 & 4.6 & 40.6 \\
\hline & 0.4 & 8.7 & 10.1 & 155.9 & 15.5 & 12.7 & 147.8 & 18.7 & 12.1 & 122.1 \\
\hline & 0.6 & 13.0 & 16.2 & 241.4 & 23.3 & 20.0 & 227.9 & 28.0 & 19.3 & 189.1 \\
\hline & 0.8 & 21.3 & 32.7 & 400.0 & 33.7 & 31.6 & 341.1 & 37.4 & 28.0 & 259.9 \\
\hline & 1.0 & 21.7 & 77.7 & 400.0 & 38.8 & 50.6 & 400.0 & 46.7 & 45.0 & 362.3 \\
\hline
\end{tabular}

Note. Intermediate values are determined by straight-line interpolation.

Change detailed analysis in coefficients has shown that the coefficient $a_{i}$ depends on the change in the percentage of reinforcement in the section insignificantly. Without significant 
error, it can be taken as a class concrete function concrete, $a_{i}=a$. Coefficients value $a$ and $b_{i}$ are given in Table 2, which also contains the formulas for the calculation of intermediate values $b_{i}$ and $\rho_{f}$ at interpolation.

Using formulas (4), (6) and equation (5) we write

$$
\frac{M_{i}}{W_{c}}=\grave{a}+b_{i} d 1 / r_{i} .
$$

Finally, from the equation (8) it will determine the curvature value

$$
1 / r_{i}=\frac{M_{i}}{b_{i} W_{c} d}+\frac{a}{b_{i} d}
$$

Equation (9) allows setting deflection formulas definition for the most common statically-defined calculation schemes. Table 3 displays the derived deflection formulas for some calculation schemes.

Analyzing them, it is clear that the second part of the formula does not depend on the type of load, but only on the type of beam and the place of the desired deflection. Consequently, if there are several power influences on the element, then the complete deflection will consist of the sum of deflections from each impact and will be determined by the formula

$$
f=\sum_{i=1}^{n} f_{e l, i}-\grave{A_{I}} \grave{a} / b_{i} d,
$$

where $f_{e l, i}$ is deflection of beams from power influences on formulas of classical materials resistance with replacement of flexural stiffness on equation $b_{i} W_{c} d ; A_{\bar{M}}$ is distribution area of single strength moment; $n$ is power influences quantity.

\begin{tabular}{|c|c|c|c|c|c|c|c|c|c|c|c|}
\hline \multirow{4}{*}{$\begin{array}{c}\text { Concrete } \\
\text { class }\end{array}$} & \multirow{4}{*}{$\begin{array}{c}a, \\
\mathrm{MPa}\end{array}$} & \multicolumn{10}{|c|}{ Reinforced proportion $\rho_{f}$} \\
\hline & & \multirow[t]{2}{*}{0.50} & \multicolumn{2}{|c|}{$\begin{array}{l}0.5- \\
1.00\end{array}$} & \multirow[t]{2}{*}{1.00} & \multicolumn{2}{|c|}{\begin{tabular}{l|}
$1.00-$ \\
2.00 \\
\end{tabular}} & \multirow[t]{2}{*}{2.00} & \multicolumn{2}{|c|}{$\begin{array}{c}2.00- \\
3.00 \\
\end{array}$} & \multirow[t]{2}{*}{3.00} \\
\hline & & & $\alpha$ & $\beta$ & & $\alpha$ & $\beta$ & & $\alpha$ & $\beta$ & \\
\hline & & \multicolumn{10}{|c|}{ Coefficients $b_{i}, 10^{-4} \mathrm{MPa}$} \\
\hline $\mathrm{C} 8 / 10$ & 1.845 & 0.262 & 0.11 & 0.30 & 0.410 & 0.21 & 0.20 & 0.614 & 0.31 & 0.15 & 0.764 \\
\hline $\mathrm{C} 12 / 15$ & 2.116 & 0.301 & 0.12 & 0.37 & 0.484 & 0.23 & 0.26 & 0.741 & 0.37 & 0.19 & 0.929 \\
\hline $\mathrm{C} 16 / 20$ & 2.146 & 0.343 & 0.14 & 0.40 & 0.544 & 0.24 & 0.31 & 0.851 & 0.40 & 0.22 & 1.075 \\
\hline $\mathrm{C} 20 / 25$ & 2.256 & 0.355 & 0.11 & 0.49 & 0.598 & 0.27 & 0.33 & 0.929 & 0.44 & 0.25 & 1.175 \\
\hline $\mathrm{C} 25 / 30$ & 2.455 & 0.368 & 0.12 & 0.49 & 0.613 & 0.23 & 0.38 & 0.992 & 0.42 & 0.29 & 1.277 \\
\hline $\mathrm{C} 30 / 35$ & 2.701 & 0.374 & 0.10 & 0.54 & 0.644 & 0.26 & 0.38 & 1.024 & 0.44 & 0.29 & 1.315 \\
\hline $\mathrm{C} 32 / 40$ & 2.769 & 0.396 & 0.13 & 0.53 & 0.663 & 0.29 & 0.38 & 1.038 & 0.36 & 0.34 & 1.376 \\
\hline $\mathrm{C} 35 / 45$ & 2.803 & 0.398 & 0.11 & 0.57 & 0.684 & 0.27 & 0.42 & 1.102 & 0.50 & 0.30 & 1.404 \\
\hline $\mathrm{C} 40 / 50$ & 2.843 & 0.419 & 0.13 & 0.57 & 0.706 & 0.26 & 0.44 & 1.148 & 0.49 & 0.33 & 1.475 \\
\hline $\mathrm{C} 45 / 55$ & 2.849 & 0.437 & 0.15 & 0.57 & 0.723 & 0.26 & 0.46 & 1.183 & 0.50 & 0.34 & 1.526 \\
\hline C50/60 & 3.188 & 0.452 & 0.18 & 0.55 & 0.725 & 0.25 & 0.48 & 1.201 & 0.48 & 0.36 & 1.563 \\
\hline & & & & & & $\underline{1}$ & $\frac{M_{e}}{b_{i} W_{c}}$ & & & & \\
\hline
\end{tabular}

Table 2. Coefficients values for calculating reinforced concrete bending elements deflections, reinforced with reinforcement $\mathrm{A} 400, \mathrm{~A} 500$, in operational stages. 
Table 3. Formulas for defining deflections for some calculation schemes.

\begin{tabular}{|c|c|c|}
\hline № & Beam calculation scheme & Formula for determining deflection \\
\hline 1 & & $f=\frac{5}{384} \frac{q l^{4}}{b_{i} W_{c} d}-\frac{l^{2}}{8} \frac{a}{b_{i} d}$. \\
\hline 2 & & $f=\frac{1}{8} \frac{q l^{4}}{b_{i} W_{c} d}-\frac{l^{2}}{2} \frac{a}{b_{i} d}$.
\end{tabular}

Let us compare the beam deflections on two supports with a uniformly distributed load in two methods: the Simpson formula, as the most accurate, and formula (9). We will accept reinforcement class $\mathrm{A} 400 \mathrm{C}$, concrete $\mathrm{C} 16 / 20$ and reinforcement proportion: 0.05 ; $0.25 ; 0.5 ; 1.0 ; 2.0 ; 3.0$ for load levels $0.6 ; 0.8 ; 1.0$. The calculation results are given in Table 4. It displays that the deflections, calculated by formula (9), are not significantly deviating from the most accurate result, even at a load level of 1.0. It allows recommending such a method for calculating deflections for practical applications.

Table 4. Reinforced concrete elements relative deflections comparison determined by different methods for the concrete class $\mathrm{C} 16 / 20$.

\begin{tabular}{|c|c|c|c|c|c|c|}
\hline $\begin{array}{c}\text { Reinforced } \\
\text { Proportion } \\
\rho_{f, \%} \%\end{array}$ & $\begin{array}{l}\text { Load } \\
\text { level }\end{array}$ & $\begin{array}{l}{\left[\frac{f}{l} \frac{1}{\lambda}\right]_{1}} \\
\text { for }(2)\end{array}$ & $\begin{array}{l}{\left[\frac{f}{l} \frac{1}{\lambda}\right]_{2}} \\
\text { for }(9)\end{array}$ & $\begin{array}{l}{\left[\frac{f}{l} \frac{1}{\lambda}\right]_{3}} \\
\text { for }(3)\end{array}$ & $\frac{\left[\frac{f}{l} \frac{1}{\lambda}\right]_{2}}{\left[\frac{f}{l} \frac{1}{\lambda}\right]_{1}}$ & $\frac{\left[\frac{f}{l} \frac{1}{\lambda}\right]_{3}}{\left[\frac{f}{l} \frac{1}{\lambda}\right]_{1}}$ \\
\hline \multirow{3}{*}{0.05} & 0.6 & 6.07 & 4.78 & 7.03 & 0.79 & 1.16 \\
\hline & 0.8 & 10.62 & 10.70 & 11.89 & 1.01 & 1.12 \\
\hline & 1.0 & 16.43 & 16.62 & 18.49 & 1.01 & 1.13 \\
\hline \multirow{3}{*}{0.25} & 0.6 & 4.13 & 4.26 & 4.38 & 1.03 & 1.06 \\
\hline & 0.8 & 6.22 & 6.71 & 6.59 & 1.08 & 1.06 \\
\hline & 1.0 & 9.20 & 9.15 & 10.15 & 0.99 & 1.10 \\
\hline \multirow{3}{*}{0.5} & 0.6 & 3.16 & 3.36 & 3.31 & 1.06 & 1.05 \\
\hline & 0.8 & 4.67 & 5.06 & 4.91 & 1.08 & 1.05 \\
\hline & 1.0 & 6.82 & 6.77 & 7.47 & 0.99 & 1.09 \\
\hline \multirow{3}{*}{1.0} & 0.6 & 2.39 & 2.60 & 2.47 & 1.09 & 1.04 \\
\hline & 0.8 & 3.49 & 3.82 & 3.65 & 1.09 & 1.05 \\
\hline & 1.0 & 5.09 & 5.04 & 5.57 & 0.99 & 1.09 \\
\hline \multirow{3}{*}{2.0} & 0.6 & 1.81 & 2.04 & 1.86 & 1.13 & 1.03 \\
\hline & 0.8 & 2.64 & 2.95 & 2.76 & 1.12 & 1.05 \\
\hline & 1.0 & 3.90 & 3.85 & 4.29 & 0.99 & 1.10 \\
\hline \multirow{3}{*}{3.0} & 0.6 & 1.56 & 1.81 & 1.60 & 1.16 & 1.03 \\
\hline & 0.8 & 2.28 & 2.60 & 2.39 & 1.14 & 1.05 \\
\hline & 1.0 & 3.43 & 3.39 & 3.81 & 0.99 & 1.11 \\
\hline \multicolumn{5}{|c|}{ Average value $x_{m}$} & 1.04 & 1.08 \\
\hline \multicolumn{5}{|c|}{ Average quadratic value $\sigma, \%$} & 12.54 & 2.48 \\
\hline \multicolumn{5}{|c|}{ Variation coefficient $v \%$} & 12.04 & 2.31 \\
\hline
\end{tabular}




\section{Examples of application of the proposed calculation method}

Calculate the one-pass reinforcement concrete beam working cross-section $b \times d=40 \times 36 \mathrm{~cm}$, made of concrete class $\mathrm{C} 50 / 60$ and reinforcement A400C. Beam Cross section beam is reinforced $4 \varnothing 18 \mathrm{~A} 400\left(A_{s}=10.179 \mathrm{~cm}^{2}\right)$ in the lower part. Estimated span $l_{0}=6 \mathrm{~m}$. It has an operational load $q=25 \mathrm{kN} / \mathrm{m}$.

Determine the deflection by close and precise methods. Solution.

1) The method of deflections linearization, by formula (2):

- Calculate the moment of working resistance and reinforcement portion section

$W_{c}=\frac{b d^{2}}{6}=\frac{40 \times 36^{2}}{6}=8640 \mathrm{~cm}^{3} ; \rho_{f}=\frac{\grave{A_{s}}}{b d} \times 100 \%=\frac{10.179}{40 \times 36} \times 100 \%=0.707 \%$,

- According to Table 1, determine linearization coefficients $a=3.188 \mathrm{MPa} ; b_{i}=\alpha+\beta \times \rho_{f}=0.18+0.55 \times 0.707=0.57 \times 10^{4} \mathrm{MPa}$;

- By formula (1, tab. 3), calculate the deflection of the beam

$f_{1}=\frac{5}{384} \frac{q l^{4}}{b_{i} W_{c} d}+\frac{l^{2}}{8} \frac{\grave{a}}{b_{i} d}=1,695 \mathrm{~cm}$.

2) Determining one curvature deflections method, by the formula (3):

- Determine the tension $\sigma_{z \grave{I}}=\frac{q l^{2}}{8 \times W_{c}}=\frac{25 \times 6^{2} \times 10^{3}}{8 \times 8640}=13.02 \mathrm{MPa}$.

- According to Table 2 where $\rho_{f}=1 \%$ determine $\sum \varepsilon=18.719 \times 10^{-4}$.

- Than $\frac{1}{r}=\frac{\sum \varepsilon}{d}=\frac{18.719 \times 10^{-4}}{36}=5.2 \times 10^{-5} \mathrm{~cm}^{-1}$.

$f_{2}=\frac{5}{48} \frac{1}{r_{m}} l^{2}=1.95 \mathrm{~cm}$.

3) Precise method for determining deflections using formula (4).

For calculation precise method, the element was broken in length by 10 sections, each having a defined curvature (see Table 5).

Table 5. Deflection definition by the precise method.

\begin{tabular}{|c|c|c|c|c|c|}
\hline $\begin{array}{c}\text { Distance from } \\
\text { the supporting } \\
\text { structure to the } \\
\text { cross-section, } \\
\mathrm{m}\end{array}$ & $\alpha_{i}$ & $\sigma_{z M}, \mathrm{MPa}$ & $\begin{array}{c}\varepsilon_{z i} \\
\times 10^{4}\end{array}$ & $\begin{array}{c}1 / r_{i} \\
\times 10^{4}, \\
\mathrm{~cm}^{-1}\end{array}$ & $\begin{array}{c}\alpha_{i} \times 1 / r_{i} \\
\times 10^{4}, \\
\mathrm{~cm}^{-1}\end{array}$ \\
\hline 0 & 0 & 0 & 0 & 0 & 0 \\
\hline 0.6 & 0.05 & 4.688 & 2.625 & 0.073 & 0.004 \\
\hline 1.2 & 0.10 & 8.333 & 9.111 & 0.253 & 0.025 \\
\hline 1.8 & 0.15 & 10.938 & 13.828 & 0.384 & 0.058 \\
\hline 2.4 & 0.20 & 12.500 & 17.362 & 0.482 & 0.096 \\
\hline 3.0 & 0.25 & 13.021 & 18.719 & 0.520 & 0.130 \\
\hline
\end{tabular}

Deflection in terms of equation (4) was $f_{3}=1.485 \mathrm{~cm}$.

As can be seen from the calculations, the error of defining the deflection by the first method was $12.4 \%$, by the second $23.85 \%$.

To check the results can be used the following online resource http://sciencehunter.net/Services/Apps/Concrete. 


\section{Conclusions}

The simplified and precise methods of deflection bending reinforced concrete elements determination according to curvature are offered. As shown by the calculations performed at operating load levels within the range of $0.5-0.85$, approximate methods give satisfactory results. In some cases, simplified methods can exaggerate the actual deflections of reinforced concrete elements. In such cases it is worth using more accurate calculation methods.

\section{References}

1. J.K. Wight, J.G MacGregor. Reinforced Concrete: mechanics and design (New Jersey: Upper Saddle River, 2009)

2. J.C. McCormac, J.K. Nelson. Design of Reinforced Concrete (Hoboken, NJ:John Wiley \& Sons, 2006)

3. D.E. Branson, HPR, 7, 78 (1965)

4. AS3600-2001. Australian Standard for Concrete Structures (S.A, North Sydney, 2001)

5. L.A. Lutz, ACI Journal, 70, 207-213 (1973)

6. R.Z. Al-Zaid, and A.H. Al-Shaikh, M. Abu-Hussein, ACI Journal, 88(2), 184-190 (1991)

7. A.M. Fikry, and C. Thomas, ACI Journal, 95(4), 444-455 (1998)

8. ENV 1992-1. Eurokode- 2. Design of concrete structure. Part 1, General rules and rules for buildings (GEN, 1993)

9. D. Kochkarev, T. Galinska, O. Tkachuk. UAE, 7(3), 176-182 (2018)

10. T. Azizov, A. Azizova, S. Al Ghadban. UAE, 7(3), 567-574 (2018) 